\title{
The Function of Glycerol, Cholesterol and Long-Chain Fatty Acids in the Nutrition of Mycoplasma mycoides
}

\author{
BY A. W. RODWELL \\ Division of Animal Health, Animal Health Research Laboratory, \\ C.S.I.R.O., Parkville, N.2, Vic., Australia \\ AND A. ABBOT \\ The Walter and Eliza Hall Institute of Medical Research, \\ Melbourne, Victoria, Australia
}

(Received 18 October 1960)

\section{SUMMARY}

Mycoplasma mycoides var. mycoides requires for growth a number of preformed lipid precursors. Media containing glycerol, cholesterol, a saturated and an unsaturated fatty acid, defatted bovine serum albumin and an additional defatted serum protein fraction (Fraction C) can supply these requirements. Albumin is believed to function by binding fatty acids, and Fraction $\mathrm{C}$ by binding cholesterol. The requirement for a saturated fatty acid can be satisfied by myristic, palmitic, stearic or margaric acid, lauric acid being less effective. The requirement for an unsaturated fatty acid can be satisfied by oleic acid, linoleic and linolenic acids being less effective. Organisms incubated in a medium deficient in either glycerol, the Fraction $\mathrm{C}+$ cholesterol system, or oleate, but adequate with respect to all other nutrients, died rapidly. Death was accompanied by lysis. Death due to a deficiency of glycerol or of cholesterol was prevented either by the omission of uracil (an essential nutrient) or by addition of chloramphenicol. Death due to oleate deficiency was not prevented by the omission of uracil. Morphological changes which resulted from each of these deficiencies are illustrated by electron micrographs. The hypothesis is advanced that glycerol, cholesterol and long-chain fatty acids are all needed for the synthesis of an undetermined cell component which is necessary for the structural integrity of the cell, and that the synthesis of this is more sensitive to a deficiency of these nutrients than is the synthesis of cytoplasm.

\section{INTRODUCTION}

A medium of partly defined composition which supported good growth of Mycoplasma mycoides was described by Rodwell (1960). It contains a heat-stable defatted serum protein fraction (Fraction C), cholesterol, an unsaturated fatty acid (or 'Tween 80'), serum albumin, glycerol, high concentrations of DL- or L-lactate and glucose. It enabled requirements for adenine, guanine, uracil, thymine, riboflavin, thiamine, nicotinic acid, $\alpha$-lipoic acid, pantothenic acid and biotin to be recognized. The amino acid requirements were not defined. The function of the medium components which serve as lipid precursors has now been investigated.

The concentration of glycerol required for maximum growth increased from about 
$5 \mu \mathrm{g} . / \mathrm{ml}$. in static cultures to about $50 \mu \mathrm{g} . / \mathrm{ml}$. in cultures rotated to give a moderate degree of aeration during incubation (Rodwell, 1960). Glycerol is rapidly oxidized to acetate and $\mathrm{CO}_{2}$ by suspensions of Mycoplasma mycoides grown aerobically. Evidence for a flavoprotein-catalysed oxidation of glycerophosphate was reported by Rodwell \& Rodwell (1954). If this pathway were irreversible, glycerophosphate could not be formed from hexose, and an exogenous source of glycerol would be needed for lipid synthesis. Experiments have shown that $\left({ }^{14} \mathrm{C}\right)$-labelled glycerol is incorporated, probably without dilution from hexose, into lipids by growing cultures of $M$. mycoides (Plackett, 1961). The quantitatively greater requirement for glycerol under aerobic growth conditions is due to the greater rate of oxidation and consequent loss of glycerophosphate for synthetic reactions. The observation that cultures of $\boldsymbol{M}$. mycoides undergo rapid lysis when growing under conditions of glycerol deficiency, but not when some other nutrients are growth-limiting, suggested that glycerol deficiency might cause the phenomenon known as unbalanced growth.

The function of sterols in the growth of mycoplasma organisms is of considerable interest, since other bacteria are not known to require or to synthesize them, except possibly in trace amounts by some species (Dauchy, Kayser \& Villoutreix, 1956; Fiertel \& Klein, 1959). Smith $(1959,1960)$ reported both cholesterol esterase (estersynthesizing) and lipase (ester-splitting) activity in a strain of human origin, and Lynn \& Smith (1960) studied the distribution of esterified and free cholesterol between the soluble and insoluble fractions of suspensions of disrupted organisms from several strains. Their results indicated that both free and esterified cholesterol were present in both fractions. Sterol was not detected in two strains of Mycoplasma laidlawii which did not require sterol for growth. It was suggested previously that cholesterol exercised a protective function during the growth of $M$. mycoides. From the experimental data it could not be determined whether cholesterol is required as a nutrient in the strict sense (i.e. whether it is incorporated into the cellular structure) in addition to the postulated protective function (Rodwell, 1956). A detoxifying function for cholesterol was also suggested to explain its growth-promoting effect for M. laidlawii (Butler \& Knight, 1960; Razin \& Knight, 1960).

A requirement for an unsaturated fatty acid for the growth of Mycoplasma mycoides was also postulated previously (Rodwell, 1956). The partly defined medium (Rodwell, 1960) contains bovine serum albumin and 'Tween 80'. The fatty acid requirements and the functions of serum albumin and of fatty acids have now been investigated.

\section{METHODS}

Organism. The strain used was the V5 strain of Mycoplasma mycoides, isolated from a case of bovine pleuropneumonia in 1936.

Medium $A$. The composition of a partly defined medium was previously reported (Rodwell, 1960). Details for its preparation are now described. It contains: $\mathrm{Na}_{2} \mathrm{HPO}_{4}+\mathrm{KH}_{2} \mathrm{PO}_{4}(\mathrm{pH} \mathrm{7.8}), 0.04 \mathrm{M}$; Na DL-lactate, $0 \cdot 14 \mathrm{M}$; cholesterol, $10 \mu \mathrm{M}$; and (per l.) glucose, 5.0 g.; bovine serum Fraction C, $0.5 \mathrm{~g}$; bovine serum albumin Fraction V (Armour), 2.0 g.; Tween 80, 5.0 mg.; glycerol, 0.05 g.; acid-hydrolysed casein (Difco, vitamin-free), $2.5 \mathrm{~g}$; tryptic digest of casein, $\equiv 2.0 \mathrm{~g}$. casein; L-cystine, $2.5 \mathrm{mg}$; L-tryptophan, 5.0 mg.; $\mathrm{MgSO}_{4} \cdot 7 \mathrm{H}_{2} \mathrm{O}, 50 \mathrm{mg}$.; $\mathrm{FeSO}_{4} \cdot 7 \mathrm{H}_{2} \mathrm{O}$, $0.25 \mathrm{mg}$.; $\mathrm{MnSO}_{4} .4 \mathrm{H}_{2} \mathrm{O}, 0.25 \mathrm{mg}$; adenine, 5.0 mg.; guanine, 5.0 mg.; uracil, 
5.0 mg.; thymine, $2.5 \mathrm{mg}$.; Ca pantothenate, $0.25 \mathrm{mg}$.; riboflavin, $0.25 \mathrm{mg}$.; pyridoxal-HCl, 0.05 mg.; nicotinamide, $0.5 \mathrm{mg}$.; thiamine, $0.5 \mathrm{mg}$.; biotin, $0.01 \mathrm{mg}$.; DL- $\alpha$-lipoic acid, $0.01 \mathrm{mg}$. The medium was distributed in $20 \mathrm{~mm}$. diameter optically matched test tubes covered with aluminium caps and sterilized by autoclaving at $10 \mathrm{lb} . / \mathrm{sq}$.in. for $10 \mathrm{~min}$. Bovine serum Fraction $\mathrm{C}$ was added to the medium before autoclaving. Bovine serum albumin Fraction $V$ and glucose were added from sterile (filtered) solutions after autoclaving the bulk of the medium. The final volume after these additions was $5 \mathrm{ml}$./tube. The $\mathrm{pH}$ value of the medium was $7 \cdot 5$.

Medium $B$. As a result of the studies on the fatty acid requirements to be described medium $\mathrm{A}$ was modified. Bovine serum albumin Fraction $\mathrm{V}$ was replaced by Fraction $\mathrm{V}$ extracted by $i s o$-octane + glacial acetic acid mixture $(19+1$; Goodman, 1957 ) at the decreased concentration of $1.0 \mathrm{~g}$./l. Tween 80 was replaced by $\mathrm{Na}$ palmitate $+\mathrm{Na}$ oleate each at $20 \mu$ mole $/ 1$. Inositol (1 mg./l.), choline chloride (1 mg./l.) and leucovorin (folinic acid) $(\mathbf{0} \cdot 25 \mathrm{mg}$./l.) were also added.

Preparation of medium constituents. Na DL-lactate was prepared from CP or AR grade lactic acid. The $\mathrm{Zn}$ salt was made, twice recrystallized, decomposed with sodium carbonate, and the remaining traces of zinc removed by successive treatments with 8-hydroxyquinoline in chloroform (Waring \& Werkman, 1942). Excess carbonate was then decomposed by boiling with additions of $\mathrm{HCl}$ until the $\mathrm{pH}$ value remained at about 7.0. Alternatively, the $\mathrm{Zn}$ salt was suspended in water and shaken with a small excess of ion-exchange resin (Amberlite IR.120, $\mathrm{H}^{+}$form). The resin was drained, washed, the supernatant fluid and washings passed through a small column of fresh resin, and the acid titrated to $\mathrm{pH} 7 \cdot 0$ with $\mathrm{NaOH}$. Solutions prepared by either method had equal activity. Several samples of CP and AR grade lactic acid when tested without purification inhibited growth at higher concentrations.

Bovine serum Fraction $\mathrm{C}$ was made from ox serum. Serum was diluted with an equal volume of water, heated to $70^{\circ}$, cooled, adjusted to $\mathrm{pH} 5 \cdot 6$ with $5 \%(\mathrm{v} / \mathrm{v})$ acetic acid, heated to $80^{\circ}$, cooled, and filtered on a Büchner funnel. The filtrate was saturated with ammonium sulphate. The orange-coloured precipitate which rose to the surface was collected by gravity filtration through folded Whatman no. 2 paper. It was suspended in a small volume of water and the suspension dialysed thoroughly against four to six changes of distilled water. The dialysed solution containing some insoluble material was adjusted to $\mathrm{pH} 4 \cdot \mathbf{8}-\mathbf{5} \cdot \mathbf{0}$, whereupon about half the protein was precipitated. The suspension was chilled to $0-2^{\circ}$, and 10 vol. cold ethanol added slowly. The precipitate was washed twice with the same volume of ethanol at $-5^{\circ}$ on the centrifuge, then successively with ethanol, ethanol + ether mixture, and ether on a Büchner funnel. The yield of cream-coloured powder was 1·5-2.0 g./l. serum taken. The product was stable indefinitely. For use in the medium, it was ground in a mortar with water, $0.05 \mathrm{~N}-\mathrm{NaOH}$ added to $\mathrm{pH} 7 \cdot 4$ (about $7.0 \mathrm{ml} . / \mathrm{g}$. powder), and the mixture stirred for about $30 \mathrm{~min}$. The concentration was adjusted to $1 \%(\mathrm{w} / \mathrm{v})$ with water, and a small amount of insoluble material centrifuged off and discarded.

Cholesterol was added to the medium as a colloidal dispersion in water. One volume of a $20 \mu \mathrm{M}$ solution in ethanol at $60^{\circ}$ was injected rapidly into $19 \mathrm{vol}$. of stirred water at $60^{\circ}$. Cholesterol dispersions were stored in evacuated Thunberg tubes in a refrigerator. To avoid precipitation it was necessary to add the cholesterol dispersion to the medium after the bovine serum Fraction $\mathrm{C}$ had been added. 
Tween 80 was purified as described by Davis (1947).

Oleic acid was purified from commercial redistilled oleic acid by precipitation of the long chain saturated fatty acids from acetone at $-20^{\circ}$, followed by five recrystallizations of the unsaturated acid from acetone at $-60^{\circ}$ (Brown \& Shinowara, 1937).

Linoleic and linolenic acids were prepared by saponification followed by bromination of the fatty acid mixtures, and would therefore be a mixture of the cis and trans isomers.

Lauric, myristic, palmitic and stearic acids were Eastman-Kodak products and were recrystallized several times from acetone. Margaric acid was a product of $\mathbf{L}$. Light and Co. (Colnbrook, Bucks). Fatty acid impurities were not detected in any of the acids by reversed-phase circular paper chromatography as described by Nowotny, Lüderitz \& Westphal (1958). Margaric acid migrated at a speed intermediate between those of palmitic and stearic acids in this solvent system. The fatty acids were added to the medium as the $\mathrm{Na}$ salts. Sparingly soluble salts were warmed to dissolve them before adding them to the medium.

Bovine serum albumin Fraction V (Armour) was heated at $56^{\circ}$ for $30 \mathrm{~min}$. at $\mathrm{pH}$ $\mathbf{7 \cdot 0}$ to inactivate lipase (Davis \& Dubos, 1946). Bound fatty acids were extracted with iso-octane containing glacial acetic acid as described by Goodman (1957). The fatty acid content of the albumin after extraction was not determined.

Tryptic digest of casein was made from 'vitamin-free' casein (Glaxo) and was charcoal-treated as described by Roberts \& Snell (1946).

The other reagents were commercial products. Stock solutions were stored in a deep-freeze cabinet and were replaced at monthly intervals.

Preparation of inocula. Organisms for inocula were grown in BVF-OS medium ('Turner, Campbell \& Dick, 1935). Cultures were centrifuged at 15,000 $\mathrm{g}$ for $15 \mathrm{~min}$., the tubes drained, the deposit washed once with $0 \cdot 4 \mathrm{M}$-sucrose solution containing $0 \cdot 01$ M-phosphate buffer $(\mathrm{pH} \mathrm{7 \cdot 0)}$ and resuspended in sucrose + phosphate solution.

Groroth tests. Duplicate tubes were seeded with about $2 \times 10^{6}$ viable elements $/ \mathrm{ml}$., and the growth estimated turbidimetrically at $660 \mathrm{~m} \mu$ at intervals during static incubation at $37^{\circ}$. Streaming birefringence was judged visually by the amount of 'swirl' when the cultures were gently agitated. In many instances the cultures were examined by dark-field microscopy.

Nutritional deficiency experiments. Replicate tubes of partly defined medium with the additions or omissions indicated in the text were seeded with inocula of $5 \times 10^{7}$ to $5.5 \times 10^{8}$ viable elements $/ \mathrm{ml}$. and were incubated at $37^{\circ}$ in an upright position without shaking. One tube of each replicate set was used for each viable count or for the preparation of specimens for electron microscopy. Two tubes of each replicate set, and also two tubes of uninoculated medium, were reserved for turbidity measurements at $440 \mathrm{~m} \mu$.

Counts of viable elements. These were made by a modification of the Miles \& Misra (1938) method, as adapted for counting Mycoplasma mycoides by Mr G. S. Cottew (personal communication).

Preparation of specimens for electron microscopy. The cultures were chilled to $0^{\circ}$, centrifuged in the cold, the pellets resuspended in sucrose + phosphate solution and the suspensions squirted into $10 \mathrm{vol}$. of sucrose + phosphate containing $4 \%(\mathrm{w} / \mathrm{v})$ formaldehyde. After standing for 4-18 hr. at room temperature they were centrifuged and the pellets washed twice and resuspended in distilled water. 


\section{RESULTS}

\section{Effect of glycerol deficiency}

Tubes of (i) Medium A, (ii) Medium A lacking glycerol, (iii) Medium A lacking uracil, and (iv) Medium A lacking both glycerol and uracil, were seeded with $5.5 \times 10^{8}$ viable elements $/ \mathrm{ml}$. Viable element counts and turbidity measurements were made at intervals during incubation for $24 \mathrm{hr}$. During this period, the viable count increased about fourfold in (i), decreased to about $15 \%$ of the number inoculated in (ii), and remained almost stationary in (iii) and (iv) (Fig. 1b). That is, a

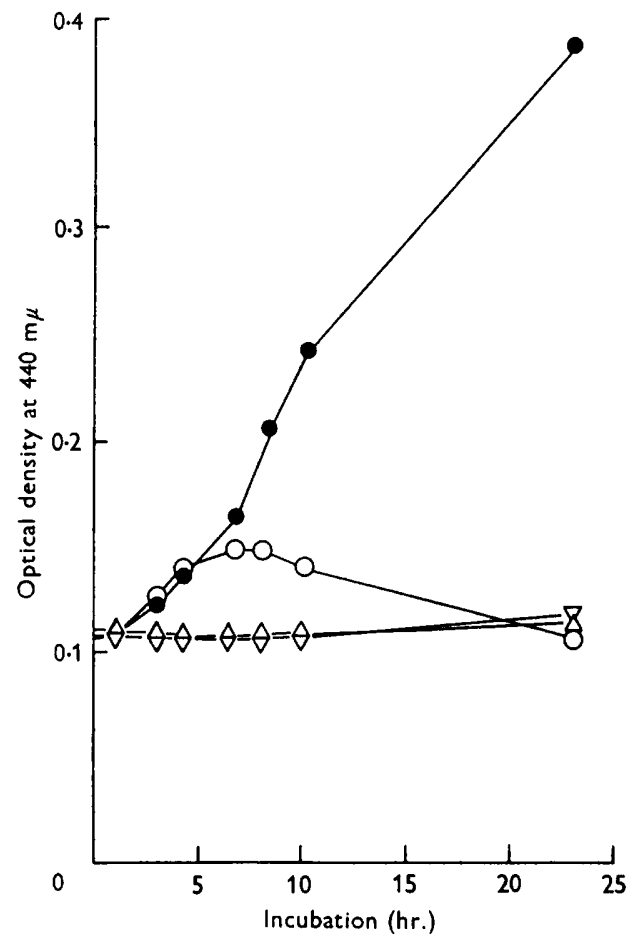

(a)

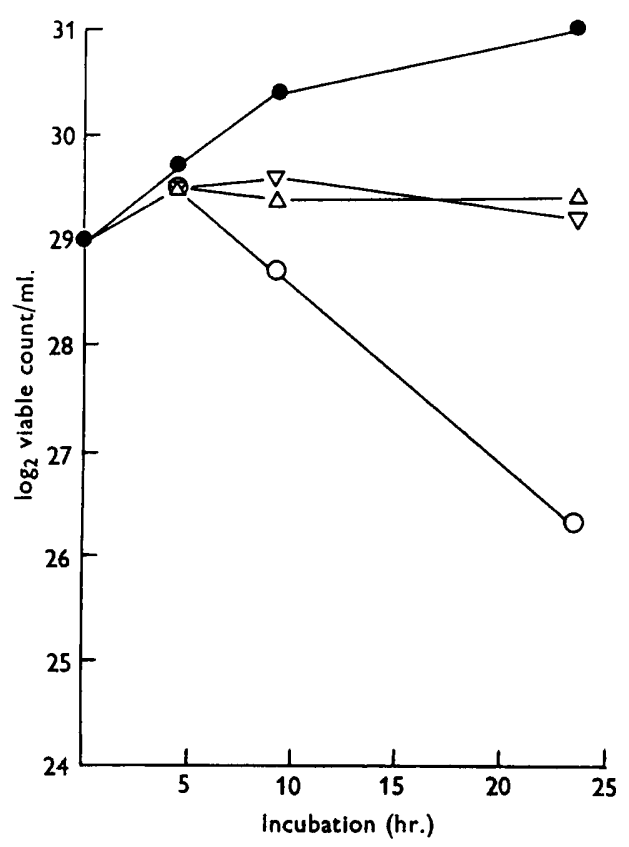

(b)

Fig. 1. The effect of the omission of glycerol and uracil on the turbidity and viability of cultures of Mycoplasma mycoides. (a) Turbidity; (b) viable element count. Complete medium; $\bigcirc$, glycerol omitted; $\triangle$, uracil omitted; $\nabla$, glycerol and uracil omitted.

deficiency of uracil prevented death which would otherwise have occurred through glycerol deficiency, throughout this incubation period. Incubation in (ii) resulted in: an early increase, followed by a decrease, in turbidity (Fig. 1 $a$ ); an early (after about $4 \mathrm{hr}$. of incubation) loss of streaming birefringence; later, an obvious increase in the viscosity of the culture, suggesting that extensive cellular lysis had occurred. Profound morphological changes culminating in lysis during incubation in the glyceroldeficient medium were evident in electron micrographs. Owing to technical diffculties, specimens for electron microscopy were obtained from a duplicate experiment on which turbidity measurements, but not viable counts, had been made. Electron micrographs prepared from cultures in (iii) (Pl. 1, fig. 3) showed a range of 
forms characteristic of the organism grown in (i) (Pl. 1, figs. 1, 2) throughout the $24 \mathrm{hr}$. incubation period. In (ii) most of the forms were enlarged within 4-8 hr. of incubation; many had shrunken appendages, and a few flattened ghost-like forms were present (Pl. 1, fig. 4). After 24 hr. of incubation there was a great preponderance of ghost-like forms, most of which contained a single, small, electron-dense granule (Pl. 2, figs. 5, 6); there were only a few electron-dense forms which were probably representative of the remaining viable forms (Pl. 2, fig. 5). After 24 hr. incubation in (iv), the forms resembled preparations from (ii) after only $4 \mathrm{hr}$. incubation (Pl. 2, fig. 7). That is, a deficiency of uracil retarded the onset of the morphological changes caused by glycerol deficiency.

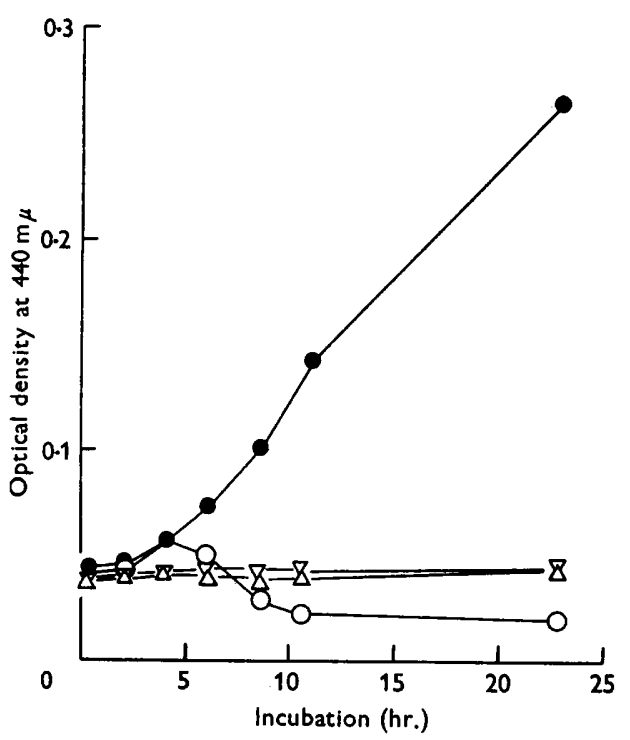

(a)

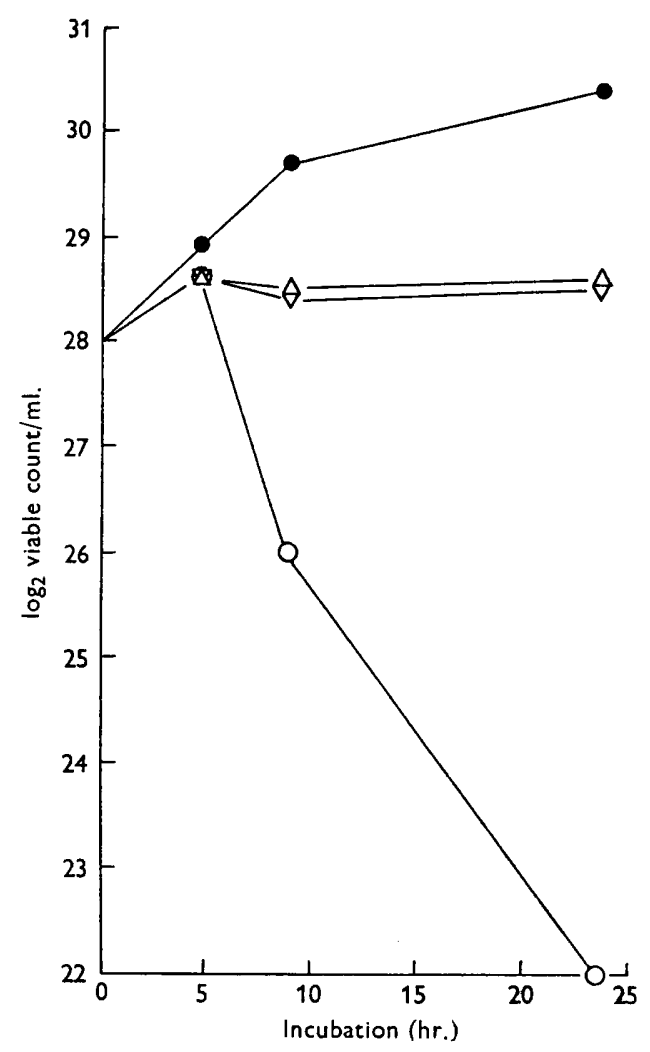

(b)

Fig. 2. The effect of the addition of chloramphenicol (CAP) on 'glycerol-less death' of Mycoplasma mycoides. (a) Turbidity; (b) viable element count. Complete medium; $O$, glycerol omitted; $\Delta$, CAP ( $\mu \mathrm{g} . / \mathrm{ml}$.) added; $\nabla$, glycerol omitted and CAP $(20 \mu \mathrm{g} . / \mathrm{ml}$.) added.

Like the omission of uracil, the addition of chloramphenicol (CAP) prevented death caused by glycerol deficiency and the associated turbidity changes (Fig. $2 a, b$ ). Viable counts remained stationary during a 24 hr. incubation period in Medium A with the addition of $20 \mu \mathrm{g}$. CAP/ml., and in glycerol-deficient medium containing $20 \mu \mathrm{g}$. CAP $/ \mathrm{ml}$. Only about $1.5 \%$ of the viable elements inoculated survived after 24, $\mathrm{hr}$. of incubation in glycerol-deficient medium. There was a maximum mortality 
rate of about $80 \%$ per generation time. The greater death rate found in this experiment as compared with that illustrated in Fig. $1 b$, may have been due to differences in the size of the inocula used in the two experiments.

\section{Effect of cholesterol + bovine serum Fraction $C$ deficiency}

Although direct evidence is lacking, it is thought that the function of bovine serum Fraction $\mathrm{C}$ is to bind cholesterol in a water-soluble assimilable form. Incubation of mycoplasma organisms in Medium A lacking both cholesterol and Fraction $\mathrm{C}$ resulted in an early loss (after about $5 \mathrm{hr}$. of incubation) of streaming birefringence,

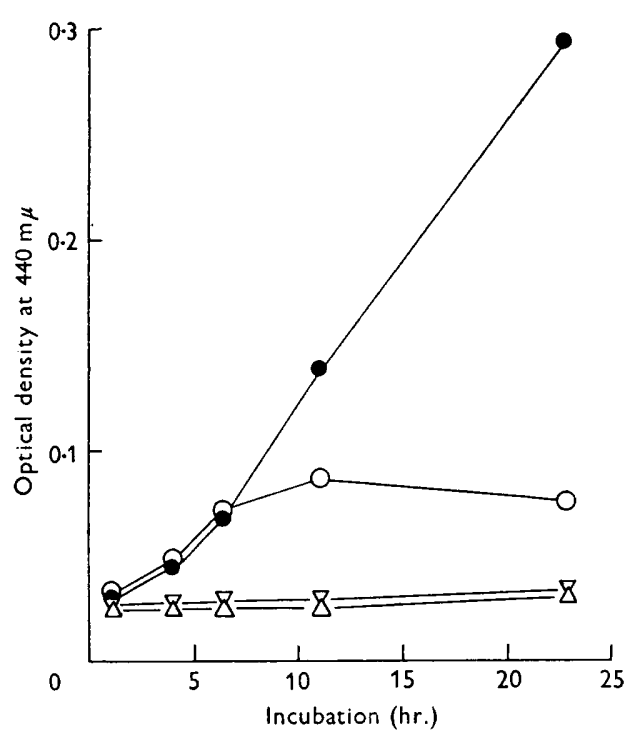

(a)

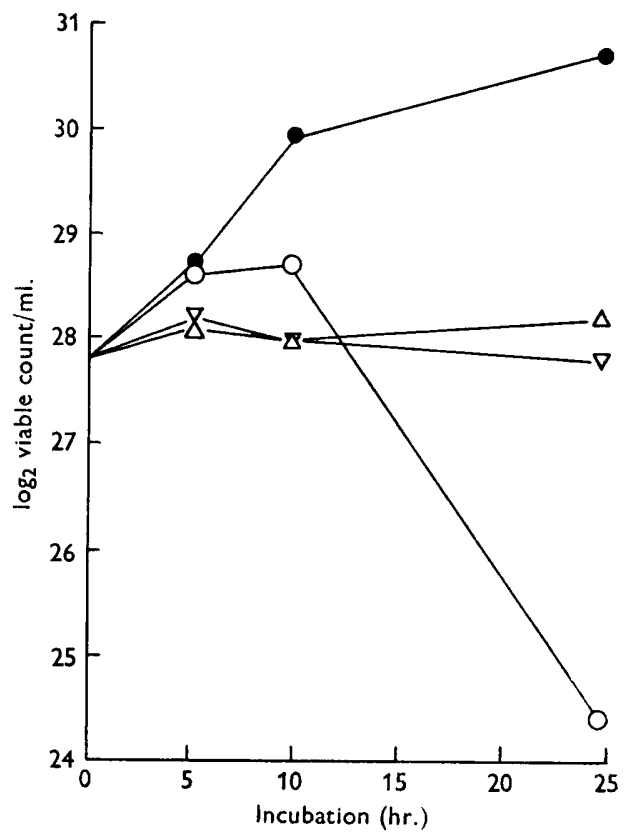

(b)

Fig. 3. The effect of the omission of cholesterol, bovine serum, Fraction $\mathrm{C}$ and uracil on the turbidity and viability of cultures of Mycoplasma mycoides. (a) Turbidity; (b) viable element count. - , Complete medium; $O$, cholesterol and bovine serum, Fraction $\mathrm{C}$ omitted ; $\triangle$, uracil omitted; $\nabla$, cholesterol, bovine serum Fraction $\mathbf{C}$ and uracil omitted.

an increase followed by a gradual decrease in turbidity (Fig. 3a) and, after about $10 \mathrm{hr}$. of incubation, a rapid decrease in viability (Fig. 3b). As with glycerol deficiency, these changes did not occur when uracil was omitted. After $5 \mathrm{hr}$. of incubation many of the forms seen were swollen, and some had tenuous outgrowths which appeared to be in the process of becoming pinched off. A tendency for the forms to aggregate when the suspensions were dried on the grids was noticeable (Pl. 2, fig. 8). After longer incubation, the material appeared to be largely aggregated into masses in which little cellular structure could be seen (Pl. 3, figs. 9, 10). It is possible that a deficiency of cholesterol + bovine serum Fraction $\mathrm{C}$ caused the forms to become more susceptible to damage during the fixing and drying processes; nevertheless, the morphological changes differed from those caused by glycerol deficiency. 
The omission of either bovine serum Fraction $\mathrm{C}$ or cholesterol singly caused decreases in viable counts, but the death rate was greater when both components were omitted (Fig. $4 a, b$ ).

\section{Requirements for long-chain fatty acids}

Medium A contains bovine serum albumin Fraction V. Tween 80 was also included, although it increased growth only slightly in the presence of Fraction V. Extraction with iso-octane + glacial acetic acid almost abolished the growth-promoting activity of Fraction $\mathrm{V}$ when Tween $\mathbf{8 0}$ was omitted. Its activity was partly restored

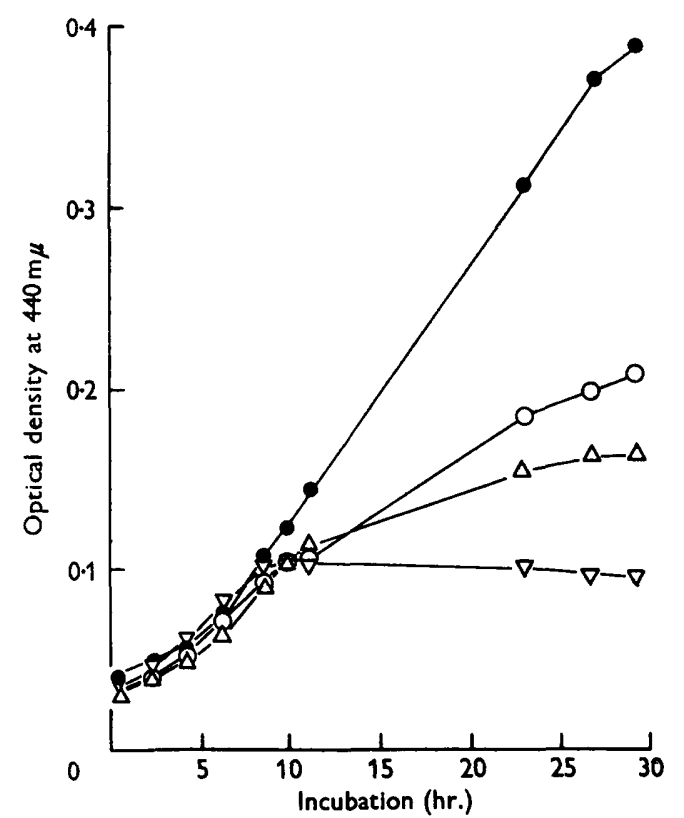

(a)

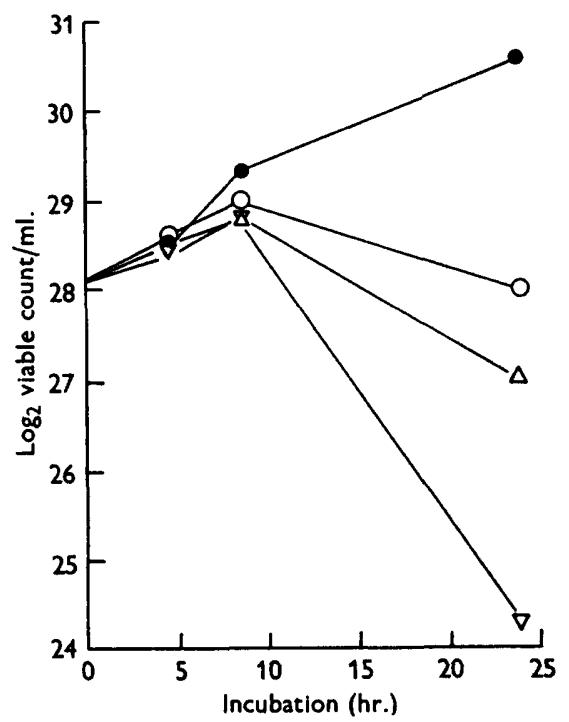

(b)

Fig. 4. The effect of the omission of cholesterol and/or of bovine serum Fraction $\mathrm{C}$, on the turbidity and viability of cultures of Mycoplasma mycoides. (a) Turbidity; $(b)$ viable element count. - , Complete medium; $O$, cholesterol omitted; $\triangle$, bovine serum Fraction $\mathrm{C}$ omitted; $\nabla$, cholesterol and bovine serum Fraction $\mathbf{C}$ omitted.

by the addition of Tween $\mathbf{8 0}$ or of oleate, and fully restored by a mixture of a saturated and an unsaturated fatty acid. Of the even-numbered saturated fatty acids from $\mathrm{C}_{12}$ to $\mathrm{C}_{18}$, palmitate and stearate were of about equal activity; laurate was less active when growth tests were performed in the presence of a constant concentration of oleate (Fig. 5). Myristate was as active as palmitate or stearate but the growth rate was slower (Fig. 6). The odd-numbered $\mathrm{C}_{17}$ acid, margaric acid, was as active as palmitic or stearic acids (Fig. 7). Oleate, linoleate and linolenate were the only unsaturated fatty acids tested; oleate was the most active, the others being active only over a very narrow concentration range (Fig. 8).

The presence of iso-octane-extracted Fraction $\mathbf{V}$ was essential. The optimum concentration in the presence of $0.02 \mu$ mole each of palmitate and oleate $/ \mathrm{ml}$. was about $1.0 \mathrm{mg} . / \mathrm{ml}$.; growth was not significantly improved by increasing the concen- 
trations of any of these components, or in the presence of more complex fatty acid mixtures.

All of these growth tests were performed in the presence of inositol, choline and leucovorin, although any influence these may have had on growth was not determined. Medium B was formulated as a result of these tests.

Cultures of Mycoplasma mycoides strain V5 in medium B showed very marked streaming birefringence, and electron micrographs showed a well developed branched mycelial morphology. It is now realized that Medium $\mathbf{A}$ is slightly deficient or disproportionate in its fatty acid composition (compare Pl. 1, fig. 1, and Pl. 3, fig. 11).

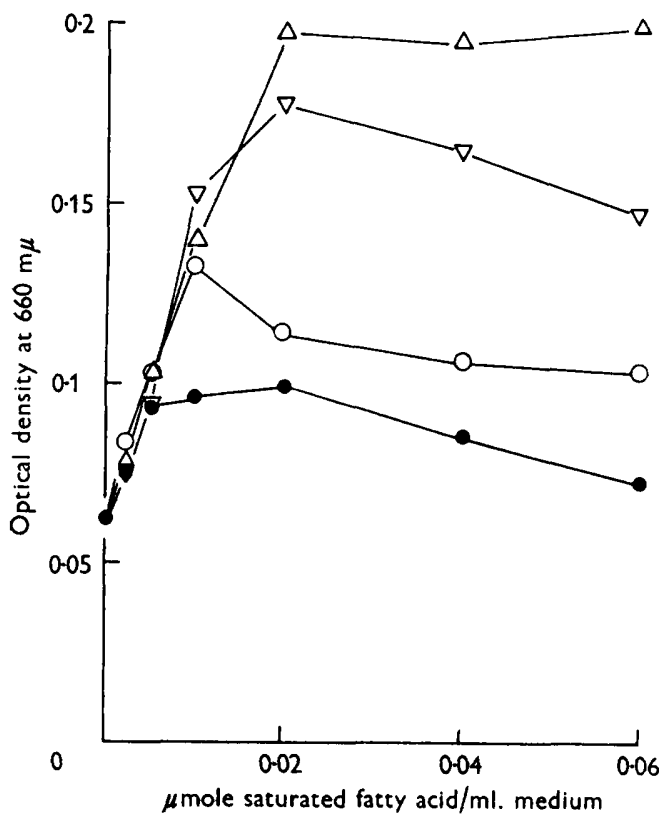

Fig. 5

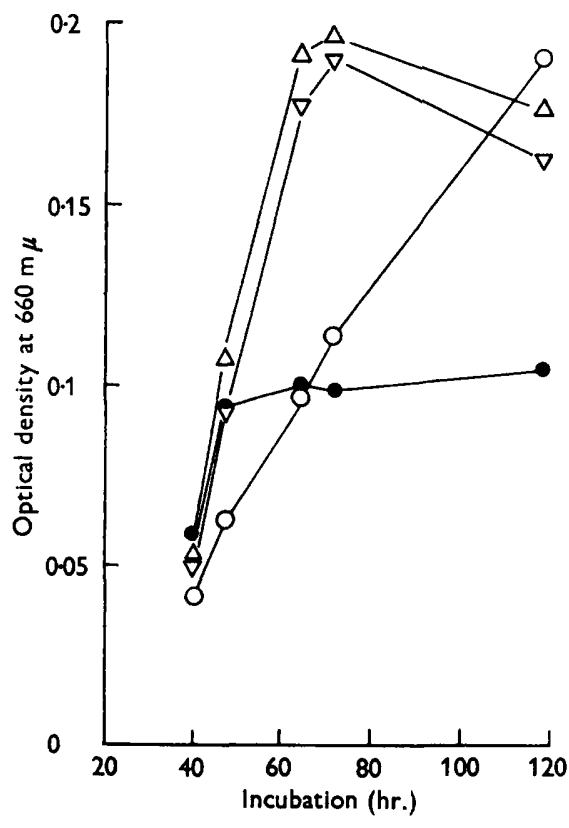

Fig. 6

Fig. 5. The effect of saturated fatty acids on growth of Mycoplasma mycoides in the presence of $0.01 \mu \mathrm{mole}$ oleate $/ \mathrm{ml}$. Incubation period $71 \mathrm{hr}$. Laurate added; $\bigcirc$, myristate added; $\triangle$, palmitate added; $\nabla$, stearate added.

Fig. 6. The effect of the $C_{12}$ to $C_{18}$ saturated fatty acids, in the presence of oleate, on the growth rate of Mycoplasma mycoides. Fatty acid concentration, $0.01 \mu \mathrm{mole} / \mathrm{ml}$. o, Laurate; $O$, myristate; $\triangle$, palmitate; $\nabla$, stearate.

\section{Effect of fatty acid deficiencies}

Replicate tubes of Medium B with the following omissions--(i) complete; (ii) without palmitate; (iii) without oleate; (iv) without palmitate and oleate; (v) without palmitate and uracil; (vi) without oleate and uracil; and (vii) without palmitate, oleate and uracil-were sown with $5.0 \times 10^{7}$ viable elements $/ \mathrm{ml}$. Viable counts and turbidity changes during incubation for $45 \mathrm{hr}$. are shown (Fig. $9 a, b$ ). The following points may be seen: $(a)$ Without added palmitate there was a large increase in turbidity, the optical density after $45 \mathrm{hr}$. of incubation reaching a value about half of that of the cultures in complete medium; increases in the viable count almost equalled those in complete medium. (b) In the absence of oleate, there was an 
increase, followed by a slow decrease, in turbidity, and, after about $15 \mathrm{hr}$. of incubation, a rapid decrease in viability. (c) In the absence of palmitate and oleate, the increase in turbidity was greater, and the decrease in viability less, than in the cultures deficient only in oleate. $(d)$ The omission of uracil did not entirely prevent an increase in the number of viable elements when incubated in medium without added palmitate, nor did it prevent a decrease in the number of viable elements in media without oleate, or without oleate and palmitate. In two other experiments, however, uracil omission slowed the decrease in the number of viable elements in medium lacking both fatty acids.

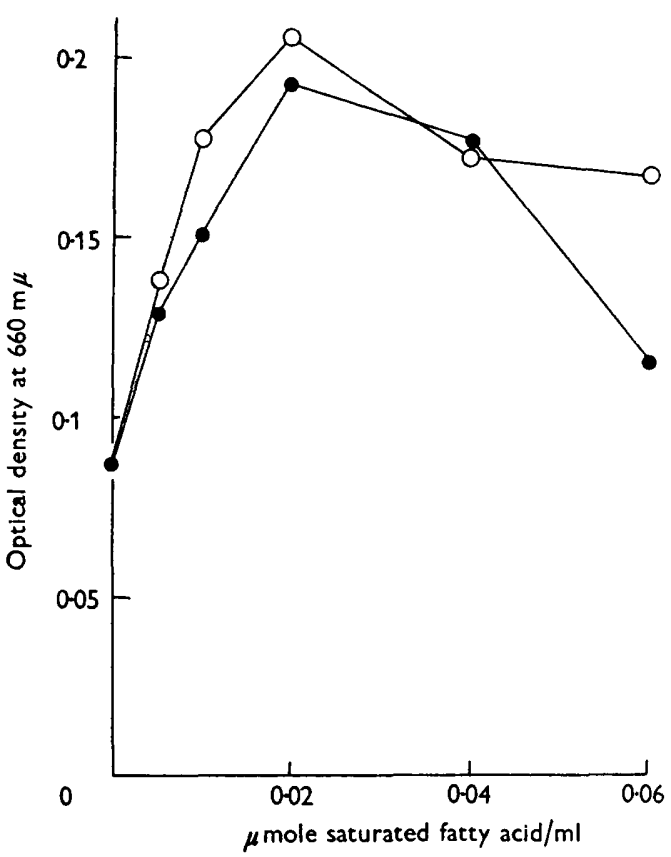

Fig. 7

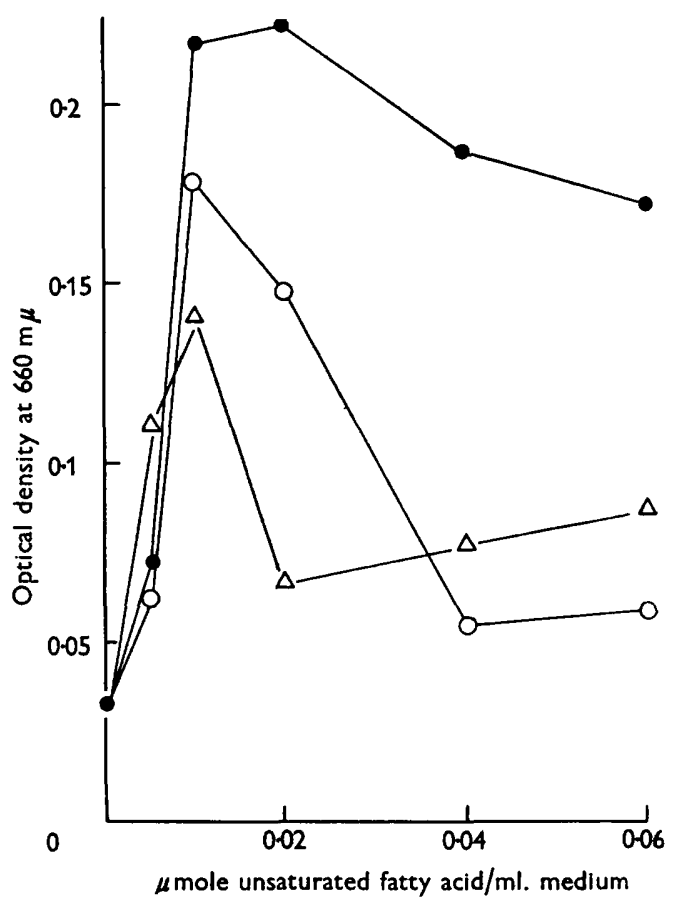

Fig. 8

Fig. 7. The effect of margarate and palmitate on growth of Mycoplasma mycoides in the presence of $0.01 \mu$ mole oleate $/ \mathrm{ml}$. Incubation period $70 \mathrm{hr}$. O, Margarate added; $O$, palmitate added.

Fig. 8. The effect of unsaturated fatty acids on the growth of Mycoplasma mycoides in the presence of $0.01 \mu$ mole palmitate $/ \mathrm{ml}$. Incubation period $71 \mathrm{hr}$. 0 , Oleate added; 0 , linolenate added; $\triangle$, linoleate added.

Electron micrographs were made from a similar series of cultures, incubated for $20 \mathrm{hr}$., in which the turbidity changes closely paralleled those shown in Fig. $9 a$. The forms seen in growth in Medium B were highly branched tangled filaments of uniform thickness (Pl. 3, fig. 11). In Medium B from which palmitate had been omitted the forms were short plump pear-shaped or oval, and many had short outgrowths (Pl. 3, fig. 12). The forms in Medium B from which oleate had been omitted were of varied morphology (Pl. 4, fig. 13); flat disks, some with a thickened rim, and some with a number of bead-like structures ranged round the periphery, were all characteristic. The forms with the thickened rim, and those with the bead-like outgrowths, 
doubtless correspond to the ring forms and to the asteroids, respectively, which have often been described in the past in morphological studies with the light microscope. An example of an asteroid is shown shadowed in Pl. 4, fig. 14, and after 'staining' with phosphotungstic acid in Pl. 4, fig. 15. The stain has penetrated the flat central portion of the form more readily than the bead-like outgrowths, as also in the ring form shown in Pl. 4, fig. 16. The form illustrated in Pl. 4, fig. 17, has five deeply stained areas (? vacuoles), some clearly defined lightly stained areas round part of the periphery, and a single lightly stained spot.

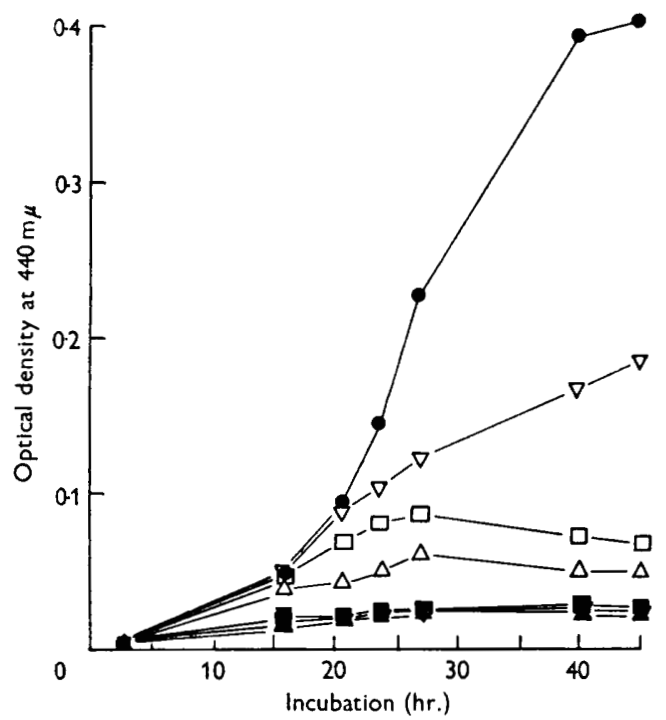

(a)

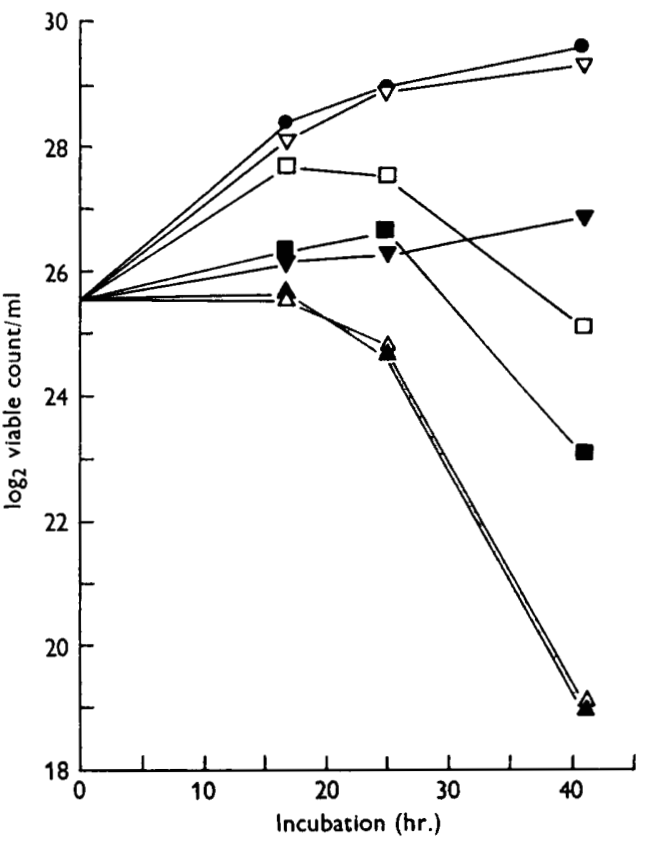

(b)

Fig. 9. The effect of the omission of palmitate, oleate and uracil on the turbidity and viability of cultures of Mycoplasma mycoides. (a) Turbidity; (b) viable element count. - Complete medium; $\Delta$, oleate omitted; $\Delta$, oleate and uracil omitted; $\nabla$, palmitate omitted ; $\nabla$, palmitate and uracil omitted; $\square$, palmitate and oleate omitted ; $\square$, palmitate, oleate and uracil omitted.

\section{DISCUSSION}

The lipid precursor requirements for growth of Mycoplasma mycoides are complex. The observations suggest that a deficiency of glycerol, cholesterol, and probably other lipid precursors causes unbalanced growth, leading to the death of viable elements and lysis. When cytoplasmic synthesis was prevented (by uracil deprivation or by the addition of chloramphenicol) the death of viable elements and lysis were also prevented. The hypothesis is advanced that these nutrients are required for the synthesis of an undefined cell component which is necessary for the structural integrity of the cell, and that the synthesis of this is more sensitive to a deficiency of these nutrients than is the synthesis of cytoplasm. It is not excluded that the death of viable elements and lysis are secondary consequences of a primary defect elsewhere in the cell. 
The effects of fatty acid deficiency require further investigation. The experiments were complicated by the probability that Medium B from which fatty acids were omitted was contaminated with suboptimal amounts of fatty acids derived from other medium constituents, e.g. from incompletely extracted bovine serum albumin Fraction V, or from the hydrolysed-casein preparations. Fatty acids may also have been carried over in significant amounts with the inoculum, because the fatty aciddependence was found to vary with the size of the inoculum. It was necessary to diminish the size of the inoculum as compared with that used for the glycerol and cholesterol experiments, and to incubate for longer periods. Under these conditions, a deficiency of oleate caused decreases in counts of viable elements and lysis which were not prevented by uracil omission. Palmitate deficiency in the experiment described did not cause decreases in viable counts, but in other experiments in which incubation was continued still longer, such decreases were beginning to occur and might have been expected to be more rapid under conditions of greater deficiency. The highly branched filaments seen in Medium B may have contained many more 'nuclear equivalents' or potential colony-forming units than the observed viable count would indicate. This may explain why the viable count was no greater than in palmitate-deficient medium (Fig. 9b). The highly branched filaments would also have a higher surface/volume ratio than the plump elements seen in palmitate deficiency. The latter forms might therefore require less oleate to maintain their viability. The experiments suggest that the ratio of saturated to unsaturated fatty acids is an important factor. Shorb \& Lund (1959) reported that a saturated and an unsaturated fatty acid, each inactive alone, were together required for the growth of two species of trichomonads; they also stressed the need for a proper balance of fatty acids. The growth-promoting activity of the $\mathrm{C}_{17}$-acid, margaric acid, for Mycoplasma mycoides may indicate that this acid is incorporated into the lipids without alteration of chain length.

Knowledge of the limiting membrane of mycoplasma organisms might help to define their relations with other micro-organisms. Mycoplasma organisms appear to lack a rigid wall structure, and are known to lack the bacterial cell-wall 'mucocomplex' (Kandler \& Zehender, 1957; Plackett, 1959). It may be suggested that the limiting membrane of Mycoplasma mycoides depends for its integrity on lipid components. Whether the galactan, described by Plackett \& Buttery (1958) and Buttery \& Plackett (1960), which accounts for about $10 \%$ of the dry weight of the organism, and which also contains a lipid component, is associated with this structure, is not known.

The morphological changes which occur during incubation of mycoplasma forms in media deficient in glycerol, cholesterol, oleate and palmitate, appear to differ. An adequate concentration of fatty acids is needed for the development of branched filaments. The appearance of ring forms, asteroids, etc., often seen in cultures incubated for long periods in crude media, may be due to an unsaturated fatty acid deficiency.

The suggestion of a general loss of structure during incubation in medium deficient in the cholesterol + bovine serum Fraction $\mathrm{C}$ system is of interest because cholesterol is believed to be interspersed between the phospholipid residues in biological membranes, and to stabilize the structure. Butler \& Knight (1960) described growth inhibition of Mycoplasma laidlawii by certain steroids, and its annulment by chol- 
esterol. It would be of interest to know whether the growth-inhibitory steroids, cause unbalanced growth with subsequent death and lysis.

The nature of the compounds into which glycerol is incorporated is being studied. A substantial part is incorporated into a cardiolipin-like compound (Plackett, 1961). Glycerophosphate polymers of the teichoic acid type described in the cell-walls of certain species of bacteria, where they replace part or all of the ribitol phosphate (Armstrong, Baddiley \& Buchanan, 1959), or large polymers of the type described by McCarty (1959), were not found. The glycerophosphate polymers forming part of the protoplast membrane of bacteria (Mitchell \& Moyle, 1956; Gilby, Few \& McQuillen, 1958) have not been characterized.

We wish to thank Dr A. W. Turner, O.B.E., and Dr P. Plackett for many stimulating discussions; Dr T. S. Gregory for helpful criticism of the manuscript; Mr G. S. Cottew for advice concerning viable element counts, and Dr G. Winter for samples of linoleic and linolenic acids.

\section{REFERENCES}

Armstrong, J. J., Baddiley, J. \& Buchanan, J. G. (1959). Teichoic acids from bacterial walls. Nature, Lond. 184, 247.

Brown, J. B. \& Shinowara, G. Y. (1937). Studies on the chemistry of fatty acids. II. The preparation of pure oleic acid by a simplified method. J. Amer. chem. Soc. 59, 6.

BUTLER, M. \& KNIGHT, B. C. J. G. (1960). Steroid growth-requirements and steroid growthinhibition of Mycoplasma. J. gen. Microbiol. 22, 483.

Buttery, S. H. \& Placketr, P. (1960). A specific polysaccharide from Mycoplasma mycoides. J. gen. Microbiol. 23, 357.

Dauchy, S., Kayser, F. \& Villoutreix, J. (1956). Présence des corps donnant les réactions des stérols chez Escherichia coli. C.R. Soc. Biol., Paris, 150, 1974.

Davis, B. D. (1947). 'The preparation and stability of fatty acid-free polyethylene sorbitan monooleate (Tween 80). Arch. Biochem. Biophys. 15, 359.

Davis, B. D. \& Dubos, R. J. (1946). Interaction of serum albumin, free and esterified oleic acid and lipase in relation to the cultivation of the tubercle bacillus. Arch. Biochem. Biophys. 11, 201.

Fiertel, A. \& Klein, H. P. (1959). On sterols in bacteria. J. Bact. 78, 738.

Gilby, A. R., Few, A. V. \& McQuillen, K. (1958). The chemical composition of the protoplast membrane of Micrococcus lysodeikticus. Biochim. biophys. acta, 29, 21.

Goodman, D. S. (1957). Preparation of human serum albumin free of long-chain fatty acids. Science, 125, 1296.

KANDLER, O. \& ZEHENDER, C. (1957). Über das Vorkommen von Diaminopimelinsäure bei verschiedenen L-Phasen-typen von Proteus vulgaris und bei den Pleuropneumonieähnlichen Organismen. Z. Naturf. 126, 725.

Lynn, R. J. \& Smiti, P. F. (1960). Chemical composition of pleuropneumonia like organisms. Ann. N.Y. Acad. Sci. 79, 493.

McCARTY, M. (1959). The occurrence of polyglycerophosphate as an antigenic component of various Gram-positive bacterial species. J. exp. Med. 109, 361.

Miles, A. A. \& Misra, S. S. (1938). The estimation of the bactericidal power of the blood. J. Hyg., Camb. 38, 732.

Mitchell, P. \& Moyle, J. (1956). Osmotic function and structure in bacteria. Symp. Soc. gen. Microbiol. 6, 172.

Nowotny, A., LüDeritz, O. \& Westphal, O. (1958). Rundfilter-Chromatographie langkettiger Fettsäuren bei der Analyse bakterieller Lipopolysaccharide. Biochem. Z. 330, 47.

Placketr, P. (1959). On the probable absence of mucocomplex from Mycoplasma mycoides. Biochim. biophys. acta, 35, 260. 
Plackett, P. (1961). A polyglycerophosphate compound from Mycoplasma mycoides. Nature, Lond. 189, 125.

Plackett, P. \& Buttery, S. H. (1958). A galactan from Mycoplasma mycoides. Nature, Lond. 182, 1236.

Razin, S. \& KNight, B. C. J. G. (1960). A partially defined medium for the growth of Mycoplasma. J. gen. Microbiol. 22, 492.

Roberts, E. C. \& SNell, E. E. (1946). An improved medium for microbiological assays with Lactobacillus casei. J. biol. Chem. 163, 499.

Rodwell, A. W. (1956). The role of serum in the nutrition of Asterococcus mycoides. Aust. J. biol. Sci. 9, 105.

RoDwell, A. W. (1960). Nutrition and metabolism of Mycoplasma mycoides var. mycoides. Ann. N.Y. Acad. Sci. 79, 499.

Rodwell, A. W. \& Rodwell, E. S. (1954). The breakdown of carbohydrates by Asterococcus mycoides, the organism of bovine pleuropneumonia. Aust.J. biol. Sci. 7, 18.

Shors, M. S. \& LUND, P. G. (1959). Requirement of trichomonads for unidentified growth factors, saturated and unsaturated fatty acids. J. Protozool. 6, 122.

Sмiтн, P. F. (1959). Cholesterol esterase activity of pleuropneumonia-like organisms. J. Bact. 77, 682.

Sмiтн, P. F. (1960). Nutritional requirements of PPLO and their relation to metabolism. Ann. N.Y. Acad. Sci. 79, 508.

Turner, A. W., Campbell, A. D. \& Dick, A. T. (1935). Recent work on pleuropneumonia Contagiosa boum in North Queensland. Aust. vet. J. 11, 63.

WARING, W. S. \& Werkman, C. H. (1942). Growth of bacteria in an iron-free medium. Arch. Biochem. Biophys. 1, 303.

\section{EXPLANATION OF PLATES}

Figs. 1-7 illustrate the morphological changes caused by incubation of Mycoplasma mycoides in medium deficient in glycerol and uracil ; figs. 8-10 those resulting from deficiency in cholesterol and bovine serum Fraction $\mathrm{C}$, and figs. 11-17 those from deficiency in palmitate and oleate. The specimens were photographed at a magnification of $\times 7200$. The final magnification of figs. 1-13 is $\times 14,400$ and that of figs. $15-17$ is $\times 36,000$.

Figs. 1-4 and 6-8 were shadowed with gold-palladium; figs. 11-13 with gold-manganin and figs. 15-17 were stained with phosphotungstic acid.

\section{Plate 1}

Fig. 1. After $8 \mathrm{hr}$. incubation in Medium A.

Fig. 2. After $24 \mathrm{hr}$. incubation in Medium A.

Fig. 3. After 24 hr. incubation in Medium A, uracil omitted.

Fig. 4. After $8 \mathrm{hr}$. incubation in Medium A, glycerol omitted.

Plate 2

Fig. 5. After $24 \mathrm{hr}$. incubation in Medium A, glycerol omitted; unshadowed.

Fig. 6. As for fig. 5, shadowed.

Fig. 7. After 24 hr. incubation in Medium A, glycerol and uracil omitted.

Fig. 8. After $5 \mathrm{hr}$. incubation in Medium A, cholesterol and Fraction C omitted.

\section{Plate 3}

Fig. 9. After $20 \mathrm{hr}$. incubation in Medium A, cholesterol and Fraction $\mathrm{C}$ omitted.

Fig. 10. As for fig. 9, from another experiment.

Fig. 11. After $20 \mathrm{hr}$. incubation in Medium B.

Fig. 12. After $20 \mathrm{hr}$. incubation in Medium B, palmitate omitted.

\section{Plate 4}

Fig. 13. After $20 \mathrm{hr}$. incubation in Medium B, oleate omitted.

Fig. 14. As for fig. 13.

Fig. 15. As for fig. 13.

Fig. 16. As for fig. 13.

Fig. 17. As for fig. 13. 
Journal of General Microbiology, Vol. 25, No. 2

Plate 1
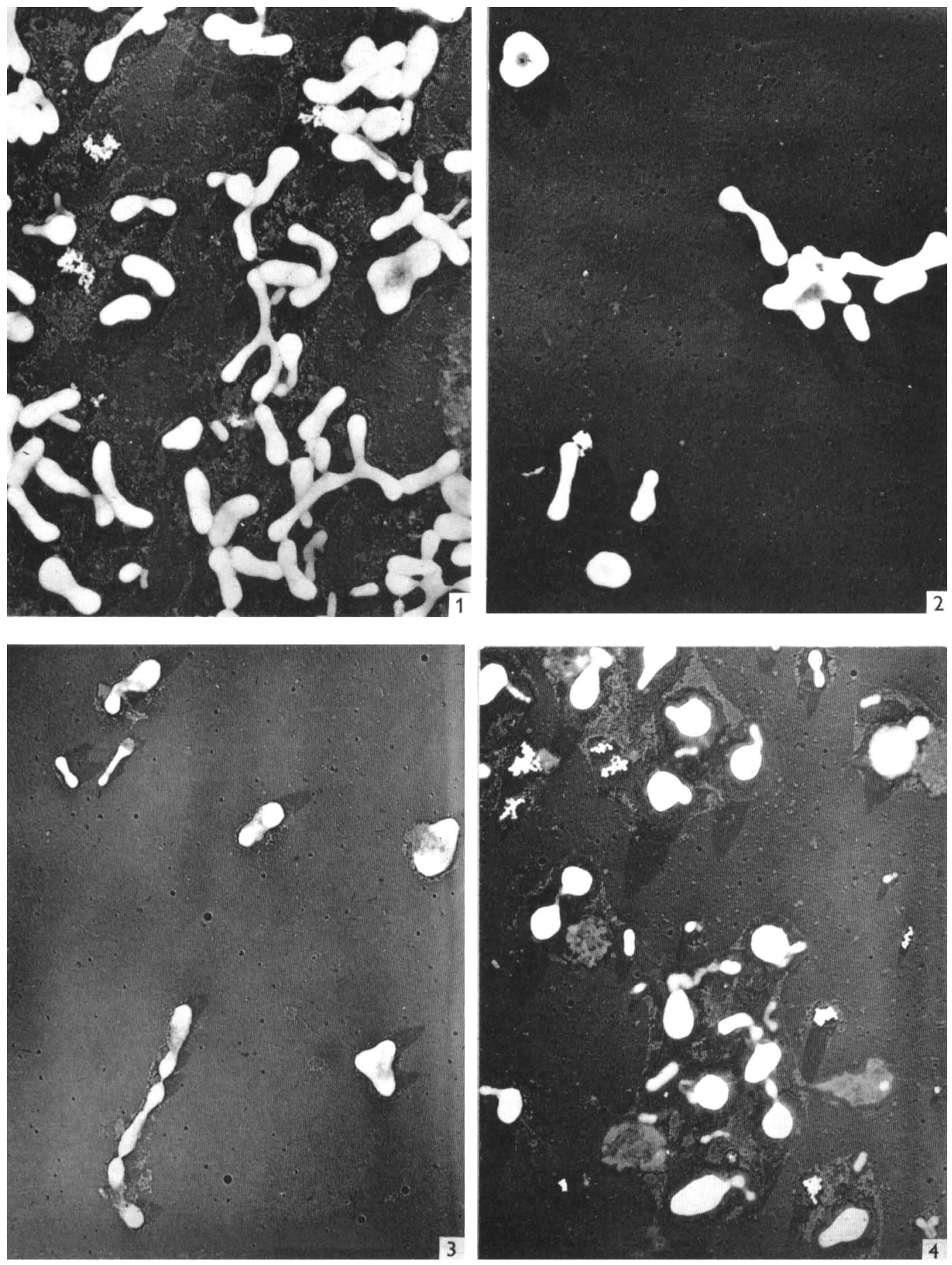

A. W. RODWELL AND A. ABBOT

(Facing $p$. 214) 
Journal of General Microbiology, Vol. 25, No. 2

Plate 2
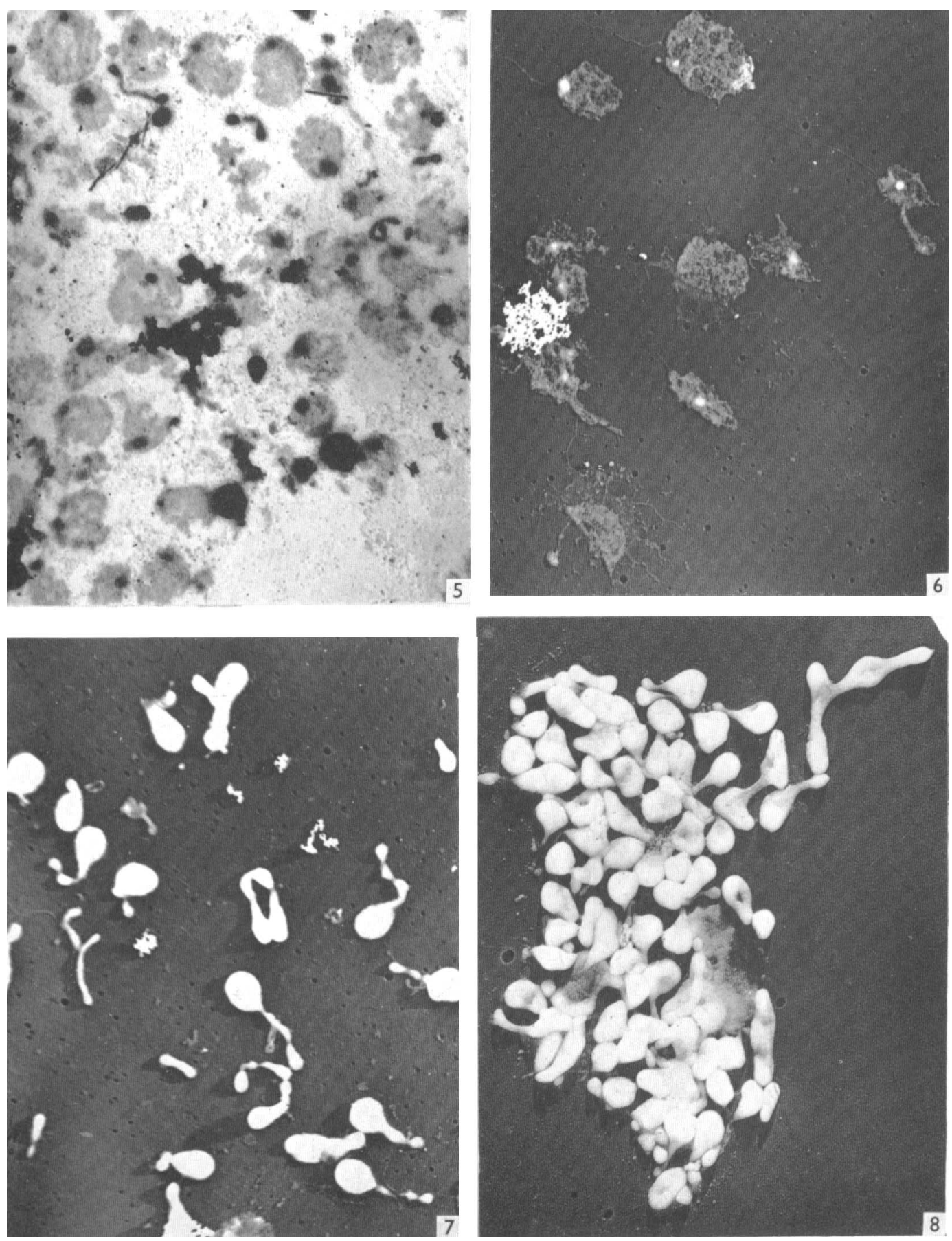

A. W. RODWELL AND A. ABBOT 

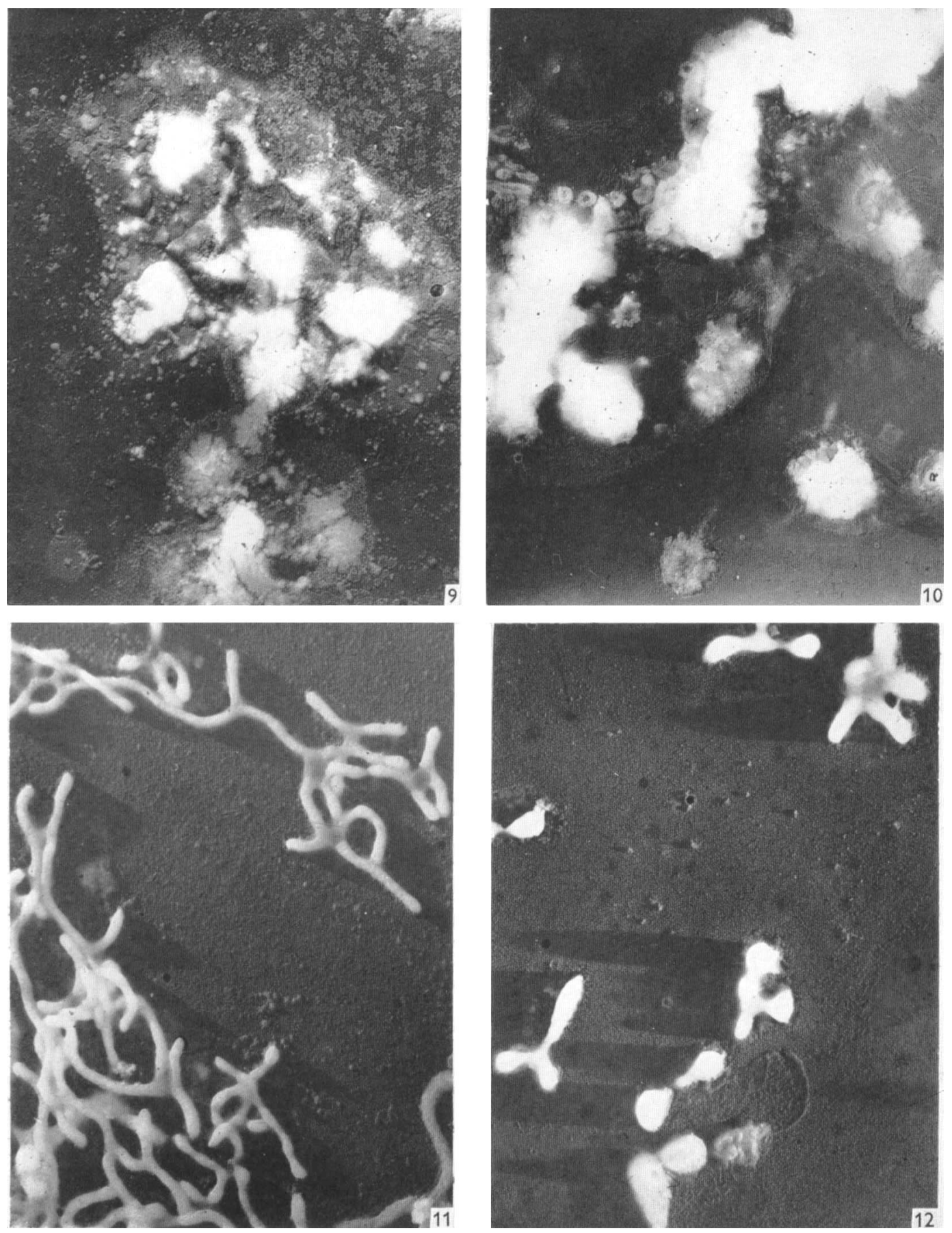

A. W. RODWELL AND A. ABBOT 

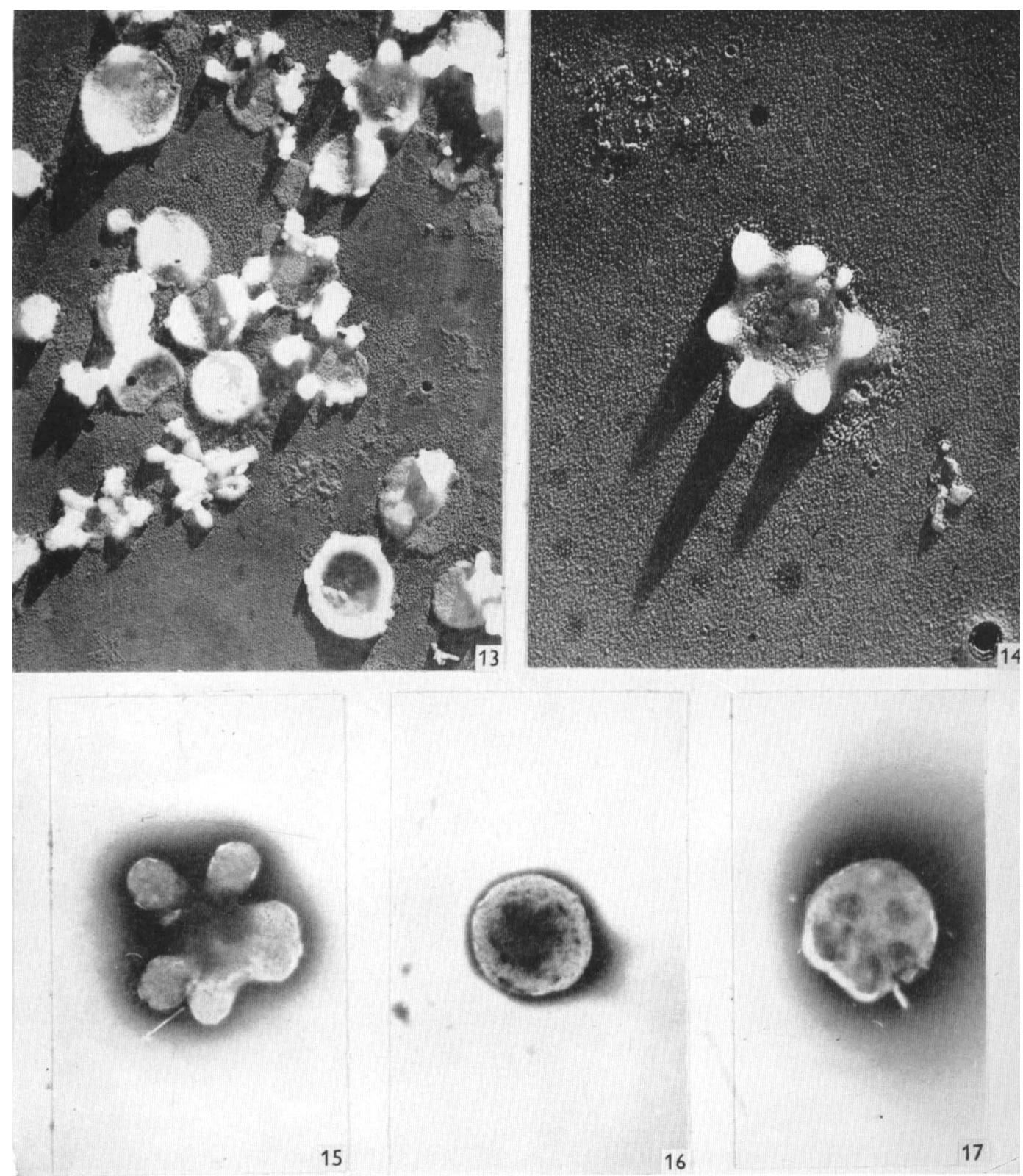

A. W. RODWEI.I, AND A. ABBOT 